\title{
Research \& Development through a gender lens - the case of Romania and Iceland
}

\author{
Ana-Maria, ZAMFIR \\ National Scientific Research Institute for Labour and Social Protection, Bucharest, Romania \\ anazamfir@incsmps.ro \\ Erla Hlín, HJÁLMARSDÓTTIR \\ University of Iceland, UNUGEST \\ erlah@hi.is
}

\begin{abstract}
For many years, gender equality has been on the agenda of various stakeholders from different sectors of activity and from different levels of action. However, information regarding the participation of women to research and development remains scarce and insufficient for assessing the progress towards equality related goals in this area. This paper aims to explore the participation of women to the research \& development sector in two selected European countries - Romania and Iceland. Thus, the present study is focused on the presence of women in a highly specialized sector that contributes to the creation of a competitive, knowledge-based society. Data on research and development personnel are analyzed from a comparative perspective in order to assess how Romania and Iceland perform in the field of gender equality in research and development sector. The findings of this paper show that women are still underrepresented in specific sectors of performance, as well as in some fields of science. Due to data lacking, analysis on the presence of women in management position in research and development couldn't be performed. So, better and more comparable statistics on gender equality issues in science is needed for ensuring a more accurate image of women participation.
\end{abstract}

Keywords: gender, research and development, human capital

JEL Classification: J16

\section{Introduction}

Women represent about half of the population world-wide and, for many years, gender equality has been on the agenda of various stakeholders from different sectors of activity and from different levels of action. Women participation to higher education has increased significantly in the last period, 
including in Romania (Pirciog, Lungu and Mocanu, 2010) and Iceland. In this context, women became more numerous among new graduates in most European countries. Also, as women became more important among the intermediate and final consumers, they need to be better represented in the process of goods and services creation, design and development (European Commission, 2012). Taking these facts into account, women participation to research and development represents an important topic of study.

The research is focused on the presence of women in a highly specialized sector that contributes to the creation of a competitive, knowledge-based society. Previous studies showed that gender disparities are persisting in demographics and productivity of research workforce. Women have made important progress in closing the scientific gender gap, but still there are lots of areas in which they still are behind (Shen, 2013). Moreover, information regarding the participation of women to research and development remains scarce and insufficient for assessing the progress towards equality related goals.

This paper aims to explore the participation of women to the sector of research \& development in two selected European countries - Romania and Iceland. According to the latest data provided by the "glass-ceiling index" measuring gender equality in the labour market, Iceland performs best among the analyzed countries, followed by Sweden, Norway and Finland (The Economist, 2017). The index integrates data regarding women participation to higher education and work, including senior jobs, payment, child-care costs, maternity and paternity rights. On the other hand, according to a different methodology that calculates a glass ceiling index for estimating the relative chance for women to reach a top position in the academic sector (as compared to men), Romania was closest to full gender equality in 2010 (European Commission, 2013). However, such data show an aggregate image of the participation of women at national level and are not useful for assessing the situation in specific areas of activity or fields of science. Official statistics on research and development personnel are analyzed from a comparative perspective in order to assess how Romania and Iceland perform in the field of gender equality in research and development sector. The findings of this paper show that women are still underrepresented in specific sectors of performance, as well as in some fields of science. On the other hand, areas and fields of science in which women are more present are highlighted. Due to data lacking, analysis on the presence of women in management position in research and development couldn't be performed. So, better and more comparable statistics on gender equality issues in science is needed for ensuring a more accurate image of women participation. 
Equity in science is a must in order to ensure a transparent and competitive society as inequalities, including gender inequalities, represent a waste of potential. Moreover, diversity in research \& development personnel is a key condition for performance (European Commission, 2012; Lee and Pollitzer, 2016). The issue of women participation to research \& development needs to be analyzed in relation with other topic of interest such as skill shortage in research and engineering, the need to develop family and work reconciliation policies and the need to reduce inequalities in society.

\section{R\&D personnel through the gender lens from a comparative perspective}

Total R\&D personnel as \% in total employment vary significantly across Europe (Figure 1). In countries such as Denmark, Luxembourg and Finland, share of R\&D personnel in total employment exceeds $2 \%$, while the EU28 average is $1.32 \%$. Also, high shares are registered by Sweden, Belgium, Austria, Iceland and Norway. Romania performs poorly to this indicator as its R\&D personnel represent only $0.38 \%$ of the total employment. Romania is followed only by Cyprus with a share of $0.32 \%$. Considering that this indicator is a very strong proxy for the potential of innovation and competitiveness at country level, the significant disparities among countries are very worrying.

According to Eurostat data for Romania, female R\&D personnel represented $0.55 \%$ of total female employment (in head count) in 2014. As total R\&D personnel accounted for $0.52 \%$ from total employment (in head count), participation of women to research and development sector is similar with the overall participation of Romanian women to the labour market. Considering the share of researchers in total employment (in head count), Romania is on the last place among European countries. In the case of Finland and Denmark, around $2.3 \%$ of total employment work as researchers. In Romania, researchers represent only $0.33 \%$ of employment, while female researchers represent $0.35 \%$.

For Iceland, the last available data are for 2015, but they are lacking for 2014. However, no major changes are to be expected in a one-year period and data could be comparable. Total R\&D personnel represented $3.31 \%$ of employment (in head count), while female R\&D personnel accounted for $2.94 \%$ of female employment (in head count). So, the participation of women to research and development sector in Island is under their overall participation to employment. The situation is improved in the case of researchers. Total researchers represent $2.13 \%$ of employment (in head count), while female researchers account for $2.02 \%$ (Eurostat). 


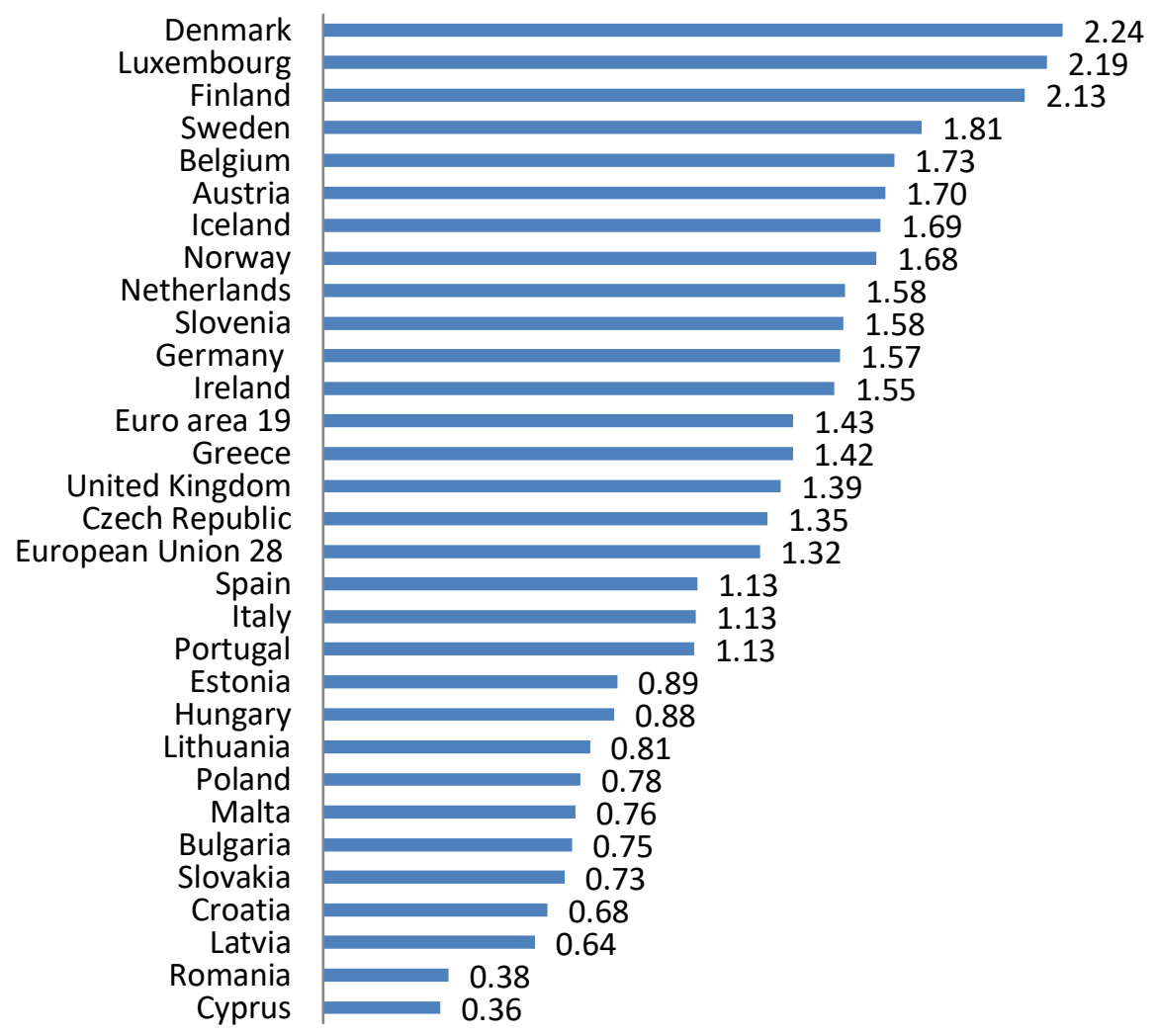

Figure 1. Total R\&D personnel: \% of total employment - numerator in full-time equivalent, 2015, Source: EUROSTAT

Overall, women are less present than men in research and development (UNESCO, 2015). However, the presence of women in research and development has increased over the years. This trend has been confirmed by the findings of an Elsevier report analyzing the gender composition of authorships across two fiveyear time periods: 1996 - 2000 and 2011 - 2015. This research has showed that, although women publish less as compared to men, the proportion of female authors has increased in time over the globe. In EU 28 countries, the share of women authors improved from $32 \%$ in the first period to $41 \%$ in $2011-2015$ years, while in the US the share increased from $31 \%$ to $40 \%$. The country that has registered the highest increase in the share of female authors is Denmark, from $29 \%$ to $41 \%$. From the field of science point of view, there are specific areas such as physical science for which, although the presence of women has been improved, their participation remains below $25 \%$. Additionally, the bibliometric analysis showed that women are less present among international collaboration 
networks. Surprisingly, data pointed out that it didn't seem to affect the citation related indicators of women as compared with men's. The report links the lower participation of women to international collaborative networks with the lower mobility of female researchers (Elsevier, 2016).

\section{Women in R\&D - the case of Romania}

Women R\&D employees count for $46 \%$ of total personnel in research and development sector. Considering the sector of performance, one could notice that women participation is more balanced in government and higher education as female personnel represent almost half of total researchers in these sectors. The situation is very different in the case of the business enterprise and private nonprofit sectors. Female personnel represent only $40 \%$ of total researchers. The significant differences in the participation of men and women to different sector of performance in R\&D could be related with differences in sectorial policies with respect to family and work reconciliation and with differences in career patterns and job characteristics. In any case, women participation is improved in sectors of performance in which they have access to employment opportunities that are adequate to their individual and career needs and expectations (Figure 2).

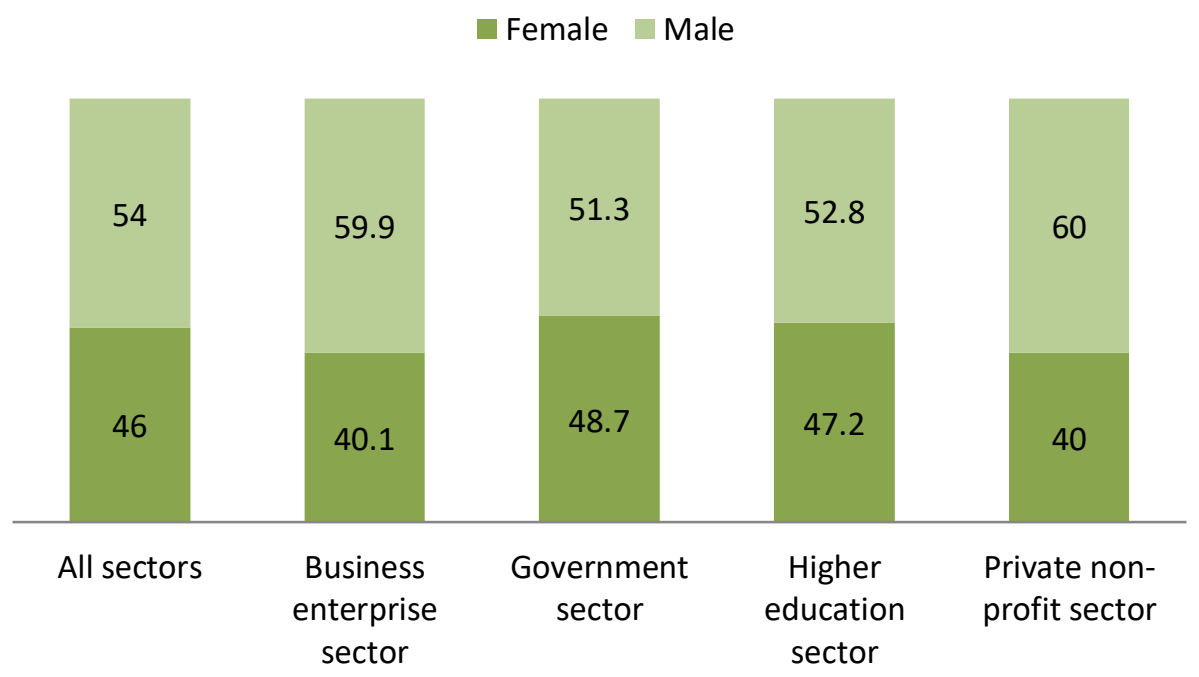

Figure 2. Researchers (in head count) by gender and sector of performance in Romania 2014 (\%), Source: Eurostat 


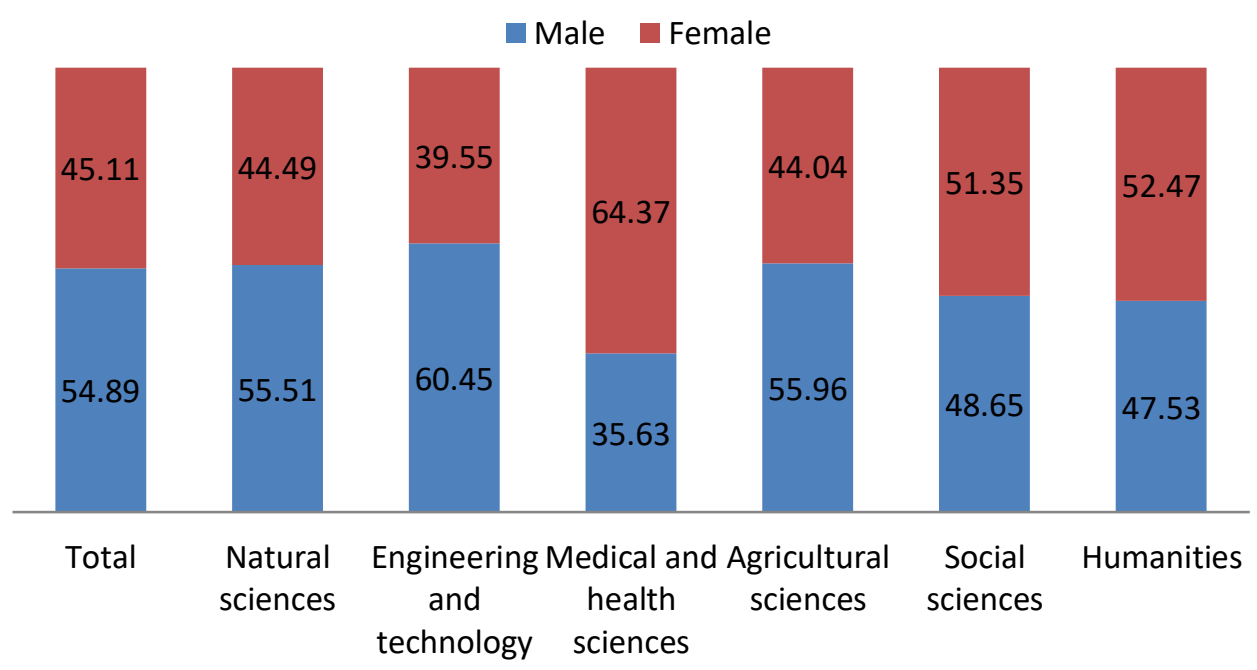

Figure 3. R\&D personnel (full-time equivalent) by gender and fields of science in Romania 2014 (\%), Source: EUROSTAT

From the point of view of the field of science, participation of women varies significantly. Share of female personnel in natural sciences and agricultural sciences is in line with the pattern registered at the level of R\&D sector - around $45 \%$. In the case of social sciences and humanities the participation of women is more balanced, reflecting their share in total population (around 52\%). On the other hand, female R\&D personnel are underrepresented in engineering and technology as they count for only $40 \%$ of total employees. In the same time, medical and health sciences could be considered a feminized scientific domain with almost $65 \%$ of personnel being women (Figure 3).

\section{Women in R\&D - the case of Iceland}

Figure 4 shows distribution of researchers by gender in Iceland in 2015. Overall, the participation of women and men is similar with the situation in Romania. However, their participation is more unbalanced within different sectors of performance as compared with Romania. Female are underrepresented in the business enterprise sector and in the Government sector. On the other hand, they account for more than half of researchers in higher education institutions. However, in spite of this more numerous participation of women, recent research has showed that the funding system and budget allocation in Iceland higher education is gender biased (Steinpórsdóttir et al., 2016). Unfortunately, no data by field of study are available for Iceland. 
- Female Male

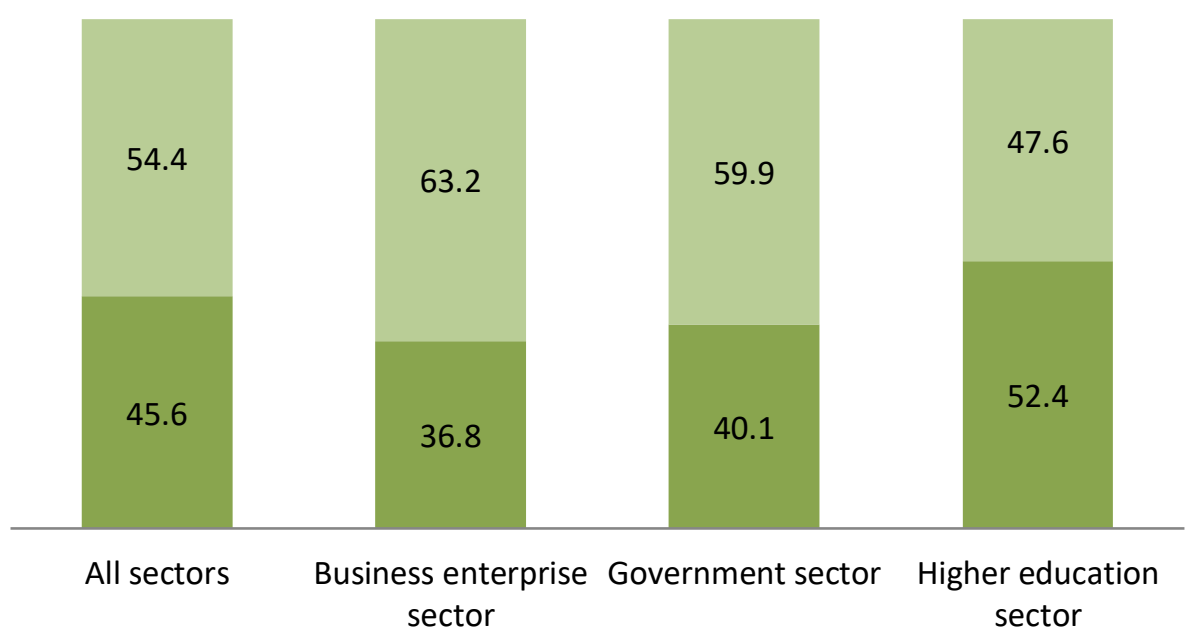

Figure 4. Researchers (in head count) by gender and sector of performance in Iceland 2015 (\%), Source: Eurostat

\section{Evolution of gender inequality in R\&D participation in Romania and Iceland}

In order to assess whether gender inequality in R\&D participation has been improving over the years, we calculated a diversity index which is used to estimate the unbalance of species within a given population. The Simpson index can be used for assessing the distribution of a population by various categories, in our case gender. It is more relevant in case of a higher number of categories, but it can be used properly for assessing the evolution of inequalities in any situation.

$$
\text { Simpson Index }(D)=\frac{1}{\sum_{i=1}^{s} p_{i}^{2}}
$$

where $s$ is the number of categories, $p_{i}$ is the proportion of individuals in category $i$ in total population. In our case, the index varies between 1 (all R\&D personnel belong to one gender) and 2 (R\&D personnel are equally divided between genders).

In Romania, the overall level of inequality is reduced and, except for a short-time deterioration in 2010, it maintains a constant trend. However, inequalities are higher in the case of business sector, where the trend is rather negative. For Iceland, the computed index indicates a deterioration of gender inequalities in the crises period in 2011. This deterioration is much more important in the business sector, where the presence of women is the weakest. 


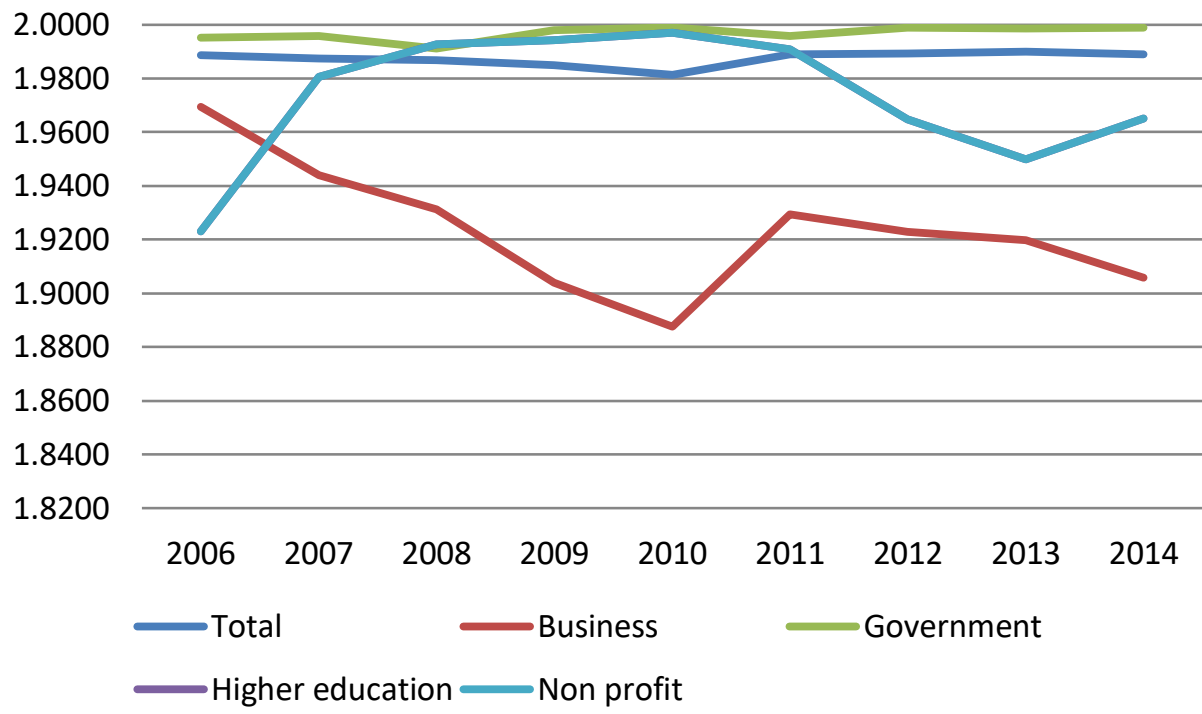

Figure 5. Simpson Index calculated for total R\&D personnel and researchers by sectors of performance and sex (in head count) in Romania, Eurostat

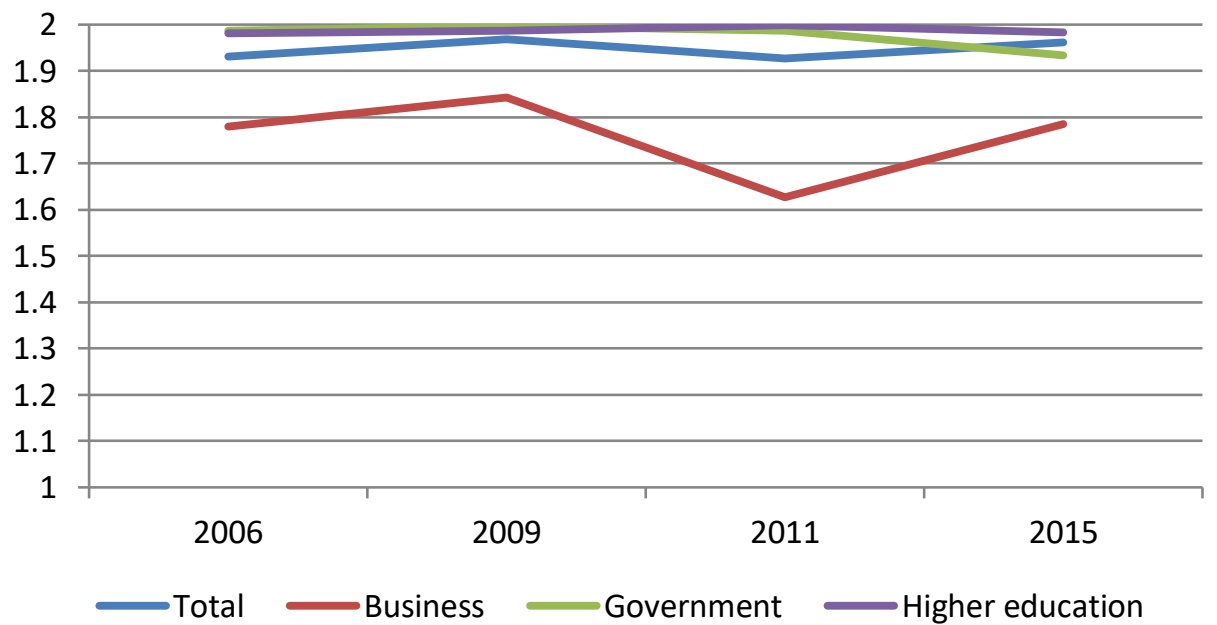

Figure 6. Simpson Index calculated for total R\&D personnel and researchers by sectors of performance and sex (in head count) in Iceland, Eurostat

\section{Conclusions}

This paper has analyzed the participation of women to research and development sector, exploring the case of Romania and Iceland. Areas in which women are less represented have been highlighted in order to better understand how to focus the gender equality policies in this field. Our results show that 
Romania and Iceland are well positioned as compared with international trends of gender participation to R\&D sector. Main conclusions are as follows:

- Volume of R\&D personnel and researchers in Romania is much reduced as compared with the other European countries. In this context, improving women participation to R\&D is more difficult.

- Overall, women participation to R\&D in Romania and Iceland is lower as against men's.

- In both Romania and Iceland, the poorest participation of women is in the business enterprise sector. So, companies, including R\&D companies need to develop better work/life policies and to improve recruitment, retention and career development for both men and women.

- The crises period affected more the participation of women in R\&D as compared to men in the analyzed countries. The negative effect has been higher in the business sector.

- Women are underrepresented in fields of science such as natural sciences, engineering and technology and agricultural sciences in Romania.

- There is a need for better and comparable statistics, especially with respect to the participation of women to top and management positions in R\&D.

ๆ

\section{References}

[1] Elsevier (2016), Gender in the Global Research Landscape, www.elsevier.com/_data/assets/pdf_file/0008/265661/ElsevierGenderReport_final_forweb.pdf

[2] European Commission (2012), Women in industrial research: A wake up call for European industry, https://ec.europa.eu/research/swafs/pdf/pub_gender_equality/wir_final.pdf

[3] European Commission (2013) She Figures 2012. Gender in Research and Innovation, http://ec.europa.eu/research/science-society/document_library/pdf_06/she-figures2012_en.pdf

[4] Lee, H., Pollitzer, E. (2016), Gender in Science and Innovation as Component of Inclusive Socioeconomic Growth. London, UK: Portia Ltd.

22-24.

[5] Shen, H. (2013), "Inequality quantified: Mind the gender gap" Nature, 495(7439), pp.

[6] Pirciog, S., Lungu, E. O., \& Mocanu, C. (2010), "Education-job match among Romanian university graduates a gender approach" in Proceedings of the 11th WSEAS international conference on mathematics and computers in business and economics and 11th WSEAS international conference on Biology and chemistry, pp. 205-210, World Scientific and Engineering Academy and Society (WSEAS).

[7] Steinpórsdóttir, F., Einarsdóttir, P ., Heijstra, T., Pétursdóttir, G. (2016), “Money talks: Gender budgeting in the University of Iceland" Icelandic Review of Politics and Administration Vol. 12, Issue 1, pp.171-194

[8] The Economist, https://www.economist.com/blogs/graphicdetail/2017/03/dailychart-0 (accessed in 25.07.2017) 
[9] UNESCO (2015), UNESCO Science Report: Towards 2030. Paris, France: UNESCO Publishing; http://unesdoc.unesco.org/images/0023/002354/235406e.pdf

\section{Acknowledgment:}

This paper was written under the project "Women's Excellence in Scientific Research and Project Management" EXCELENTFEM, Financed by the R014 Program "Research in Priority Areas" EEA Financial Mechanism 2009-2014, contract 22BIL- 31.03.2017 